\title{
CINEMA NEGRO NA EDUCAÇÃO ANTIRRACISTA: uma possibilidade de reeducação do olhar
}

\author{
Hélio Lucio dos Reis Ventura \\ Samuel Silva Rodrigues de Oliveira \\ Roberto Borges
}

\section{Resumo}

Este artigo parte da atual disputa de conceituação daquilo que tem sido chamado "Cinema Negro". Analisa o "Cinema Novo", por onde os corpos negros passaram a surgir nas telas do cinema não mais como exceção, mas ainda com graves problemas de representação. Nesse caminho, perpassa por uma análise do "Dogma Feijoada", manifesto marco das grandes inflexões que se deram na produção de cinema no Brasil. Argumenta que as lutas estéticas e políticas do Cinema Negro operam transformações no imaginário social, rompendo com o embranquecimento da linguagem cinematográfica e fomentando novas formas de narrar as experiências dos afro-brasileiros. Para finalizar, inserimos uma breve discussão da Lei n. 10.639/2003 e argumentamos que espaços de formação para além da escola oficial são importantes e necessários na construção de cidadão conscientes de seu papel antirracista.

Palavras-chave: cinema negro; educação antirracista; Lei n. 10.639/2003

\section{ON BLACK CINEMA TOWARDS AN ANTI-RACIST EDUCATION:} a possible way to reshape one's (point of) view

\begin{abstract}
This text takes it as a starting issue the present dispute on the concept of the so-called "Black Cinema". It analyzes the Brazilian New Wave / Nouvelle Vague movement on Cinema ("Cinema Novo"), whose films began to depict black bodies under a different approach/light, i.e., no longer as 'exceptions'. Nonetheless, such films still bear serious problems about the representation. Therefore, this text presents an analysis of the film "Dogma Feijoada" ("Bean Stew Dogma" — an approximated translation), which is a landmark manifest on the great inflections that have taken place in the Brazilian film production. The present article also arguments that the Black Cinema, in both aesthetical and political disputes, make changes possible on the social's common sense, breaking apart from the whitening of the cinematographic language, and increasing new ways of narrating African-Brazilian people's experience. In order to wrap up the discussion presented here, we briefly debate on Law n. 10.639/2003, and we argue that the loci aimed at educating, besides and beyond the official educational system, are of paramount importance and extremely necessary for the construction of fully aware citizens regarding their roles in an anti-racist agenda.
\end{abstract}

Keywords: black cinema; anti-racist education; Law n. 10.639/2003

\section{CINE NEGRO EN LA EDUCACIÓN ANTIRRACISTA:} una posibilidad de reeducación de la mirada

Resumen

Este artículo parte de la actual disputa de conceptualización de lo que se ha llamado "Cine Negro" en Brasil. Analiza el movimiento artístico brasileño "Cinema Novo", donde los cuerpos negros comenzaron a aparecer en las pantallas de cine ya no como una excepción, sin embargo, con serios problemas de la representación. De esta manera, desarrolla un análisis del "Dogma Feijoada", un hito manifiesto de las grandes inflexiones que tuvieron lugar en la producción de cine en Brasil. También argumenta que las luchas estéticas y políticas del "Cine Negro" provocan transformaciones en el imaginario social, rompiendo con el blanqueamiento del lenguaje cinematográfico y fomentando nuevas formas de narrar las experiencias de los afrobrasileños. Para 
concluir, insertamos una breve discusión de la Ley n. 10.639 / 2003 y argumentamos que los espacios de capacitación más allá de la escuela oficial son importantes y necesarios para la construcción de ciudadanos conscientes de su papel antirracista.

Palabras clave: cine negro; educación antirracista; Ley n. 10639/2003

\section{CINEMA NEGRO}

Ainda não há consenso a respeito da conceituação do que tem sido chamado de Cinema Negro no Brasil, no entanto, tomando como base o Dogma Feijoada (CARVALHO, DOMINGUES, 2018), de que trataremos adiante, propomos algumas características que, a nosso ver, podem se constituir como marcas distintivas deste cinema, a saber: produção majoritariamente composta por pessoas negras, representatividade de corpos negros, protagonismo de atores e atrizes negros e negras, personagens negros e negras com subjetividade densa, e personagens com características não estereotipadas.

A princípio, o cinema de "assunto negro" ${ }^{1}$ (NEVES, 2018) surgiu no nevrálgico bojo do Cinema Novo, um dos mais importantes movimentos cinematográficos do Brasil, que teve início nos anos 1960 e que lançou diretores como Glauber Rocha, Nelson Pereira dos Santos e Cacá Diegues. Disposto a subverter tanto a maneira de realizar os filmes, quanto a forma de pensar as relações entre cinema e sociedade, os produtores de cinema envolvidos com o Cinema Novo criaram uma estética única e visceral, que causou uma ruptura em relação ao que era produzido no país até então, e mudou a história do cinema brasileiro. Essa estética, no entanto, não deu conta de atender a necessária representatividade de pessoas negras com a complexidade inerente às narrativas dos dramas humanos. Isso movimentou atores, atrizes, produtores e diretores negros e negras e os impeliu a buscar outros formatos de produções cinematográficas que contemplassem seus anseios e necessidades, desde a concepção da obra até o produto acabado, tanto diante quanto por detrás das câmeras. Isso significa que o Cinema Negro surge para reivindicar a ocupação de espaços cujo protagonismo no audiovisual foi, historicamente, negado às pessoas negras.

Ao dizer que "[...] o Cinema Novo foi responsável pela disseminação de ideias antirracistas ao trazer o negro para o protagonismo de suas produções" (SANTOS, 2013, p. 102), o autor nos faz refletir se era este o objetivo do Cinema Novo, ou se era produzir um cinema que retratasse "o povo" e, pelo fato de, como se sabe, a pobreza extrema sempre ter tido, e continuar tendo, cor e "raça" no Brasil (OSORIO, 2019), negros e negras terem seus corpos inseridos na nova estética para, exclusivamente, funcionarem como representatividade do "povo" e da "luta de classes". Não obstante o negro ser "utilizado" em produções fílmicas do Cinema Novo para representar as classes populares, isso não se deu sem estereotipia da figura do afrodescendente e com a rara existência de uma representação mais crítica ou com densidade subjetiva. Esse tipo de quebra de paradigma só ocorreu a partir das produções do que tem sido chamado de Cinema Negro (LOBO, 2015, p. 1631). Interpretamos que, por mais que o Cinema Novo representasse uma ruptura com certos padrões arraigados socialmente, ele não só não combateu, mas acabou, possivelmente, por reiterar a visão negativa / estereotipada que se tinha do negro no Brasil. Podemos dar como exemplo disso a produção Xica da Silva ${ }^{2}$ (1976) de Cacá Diegues, que traz um corpo de mulher negra objetificado, e reforça a imagem da mucama sexualizada e da maior disponibilidade da mulher negra para tal propósito, entre outros estereótipos retratados no filme.

${ }^{1}$ Ganga Zumba, de Carlos Diegues, é um dos filmes de assunto negro produzido pelo Cinema Novo, inteiramente baseado e desenvolvido sobre o problema da cor e da luta pela liberdade. Nele, os personagens existem em função delas; vivem, lutam, morrem e se imortalizam por elas (NEVES, 2018, p. 184).

${ }^{2}$ Xica da Silva (BRASIL, 1976). Gênero: Comédia / Drama Duração: 1h57min . Direção: Cacá Diegues. Figurino: Luiz Carlos Ripper. Música: Jorge Ben Jor, Roberto Menescal. Produção: Jarbas Barbosa, Hélio Ferraz, José Oliosi, Airton Correa. 
O Cinema Negro marca, então, um posicionamento diferenciado de cineastas diante da representação do indivíduo e da coletividade negra, que refuta um modelo hegemônico reprodutor de uma inferiorização dos afrodescendentes. Busca, portanto, um reposicionamento do negro, em uma postura de afirmação estética e cultural, contrapondo-se à hegemonia eurocêntrica (PRUDENTE, 2006, p. 49). Os anos 1970 marcaram a primeira onda de "diretores negros" no cinema brasileiro: Antônio Pitanga, Waldyr Onofre, Odilon Lopes e Zózimo Bulbul. Ressalta-se ainda a primeira coprodução brasileira-nigeriana com o filme $A$ Deusa Negra, dirigido por Ola Balogum, e progatonizado por Zózimo Bulbul, Jorge Coutinho, Sônia Santos e Lea Garcia (1978) ${ }^{3}$ (STAM, 2008, p. 390-399). Como salientou Carvalho, após essa primeira geração, outros produtores(as) e diretores(as) assumem essa pauta estética e política do Cinema Negro e estabelecem diferentes projetos para alterar o campo do cinema e audiovisual (CARVALH O, 2006, p. 26-30)

O Cinema Negro surgiu também como uma reação aos impactos do Movimento pelos Direitos Civis dos EUA na dramaturgia, não apenas daquele país, como também em outros, como no Brasil. As lutas antirracistas e as conquistas de direitos civis e políticos dos afro-americanos nos Estados Unidos da década de 1960 ensejou uma cinematografia e um audiovisual distintos, comprometidos com a ruptura dos regimes racializados de representação que estereotipavam e subalternizavam negros (HALL, 2013, p.178-189; HOOKS, 2019, p. 214-242). A novela Vidas em conflito $(1969)^{4}$ e o filme Compasso de espera $(1973)^{5}$, ambos protagonizados por Zózimo Bulbul, refletiam a produção norte-americana da época, influenciados pelos movimentos por direitos civis, por meio de filmes como, por exemplo, Adivinhe quem vem para o jantar? $(1967)^{6}$, entre outros (CARVALHO, 2005, p. 80).

Nessa direção, o manifesto Dogma Feijoada, citado no início desse texto, problematizou a sub-representação do negro nas produções fílmicas e demais produções audiovisuais, através do Manifesto Gênese do Cinema Negro Brasileiro, escrito pelo cineasta paulista Jeferson De (CARVALHO, DOMINGUES, 2018). De forma irônica, Jeferson De parodiou o nome de um manifesto lançado em Copenhague em 1995, intitulado Dogma 95, pelos diretores dinamarqueses Lars von Trier e Thomas Vintberg que criticavam os blockbusters propondo um cinema experimental. Esse manifesto ditava dez linhas gerais - que ficaram conhecidas como "votos de castidade" - que as produções fílmicas deveriam seguir para se tornar mais realistas. A provocação de Jeferson De continuou, ao conferir ao "seu dogma" o nome de "feijoada", para se referir aos cineastas negros. Enquanto o "dogma europeu" remetia a uma rigidez, o "dogma tupiniquim" era flexível, permitia transgressões, como a própria feijoada, prato da culinária afro-brasileira que aproveita ingredientes tidos como menos nobres e que se tornou uma marca de brasilidade (CARVALHO, DOMINGUES, 2018, p. 5).

Redigido em 1999, a primeira versão do documento, antes de vir a público, foi debatida por professores da Escola de Comunicação e Artes da Universidade de São Paulo (ECA/USP),

\footnotetext{
3 A Deusa Negra (Brasil/Nigéria, 1978). Gênero: Drama. Duração: 1h35min . Direção: Ola Balogun. Figurino: Raquel Trindade. Cenografia: Sebastião Januário. Música: Remi Kabaka. Produção: Older Costa, Cristina Fernandes, André Vasconcellos.

${ }_{4}^{4}$ Telenovela produzida e exibida pela TV Excelsior de 19 de fevereiro a 23 de julho de 1969, escrita por Teixeira Filho e dirigida por Henrique Martins.

${ }^{5}$ Compasso de Espera (Brasil, 1973). Gênero: Drama. Duração: 1h38min. Direção, roteiro e produção de Antunes Filho. Música: Charles Fernando Oliveira. Fotografia: Jorge Bondanzky. Cenografia: Laonte Klawa.

6 Adivinhe Quem Vem para Jantar (EUA, 1967). Gênero: Drama / Comédia dramática. Duração: 1h48min. Direção: Stanley Kramer. Roteiro: William Rose. Sinopse: Joey foi criada por seus pais para ter a mente aberta, mas a situação muda quando ela traz um noivo negro para casa. Embora decidida a se casar apesar de qualquer objeção, seu noivo quer a aprovação dos pais dela e dos seus também. Entre outras premiações, foi vencedor do Oscar de Melhor Atriz e Oscar de Melhor Roteiro Original.
} 
produtores e documentaristas, e examinado em um festival de cinema realizado no Museu da Imagem e do Som (MIS/SP) no mesmo ano. Ao ser lançado no $11^{\circ}$ Festival Internacional de Curtas Metragens de São Paulo em 2000, e ser publicado em veículos como a Folha de São Paulo e o Jornal do Brasil, causou polêmica, com reações tanto adversas quanto de apoio (CARVALHO, DOMINGUES, 2018, p. 6).

Para entender o contexto da motivação do Manifesto Dogma Feijoada, é necessário voltar uma década. A extinção da Embrafilme ${ }^{7}$ no início do governo Collor (1990-1992) causou danos devastadores à indústria cinematográfica nacional, reduzindo drasticamente a produção de filmes e causando forte crise no setor, que só retomou novo fôlego em meados dos anos 1990, por efeito de leis como a Rouanet ${ }^{8}$ e a do Audiovisual ${ }^{9}$. Nessa fase, as produções tinham maior preocupação com o mercado e pouco refletiam sobre questões de cunho social. Dessa forma, não é de se surpreender que a imagem e a representação nas telas do cinema brasileiro fosse quase que exclusivamente de pessoas brancas (CANDIDO et al., 2014). Como os padrões ligados aos corpos brancos sempre foram associados, de maneira profundamente essencialista, ao universal, a ausência de atores e atrizes negros e negras, ocupando papéis que não fossem subalternizados ou estereotipados, não causava estranheza nem desconforto para boa parte da população, sobretudo para quem é entendido no Brasil como branco ou branca (ARAÚJO, 2000).

É importante ressaltar o que Joel Zito Araújo, no livro A negação do Brasil (2000), elencou e chamou de "[...] os 5 estereótipos básicos do cinema industrial", comuns no audiovisual estadunidense e reproduzido no brasileiro, a saber: 1) o "mulato trágico", que vivia ansiando o modo de vida do branco, o que invariavelmente não tinha um bom desfecho; 2) o "Tom", negro dócil que "sabe o seu lugar" e não raramente defendia seu senhor; 3) a "Mammie", versão feminina do Tom, amiúde interpretada por mulher gorda, misto de ama de leite e governanta, que nutre carinho pelos patrões pois se entende parte da família; 4) o "coon", malandro, vadio, desocupado, indolente, boêmio; 5) o "buck", negro brutal, animalizado e hipersexualizado (ARAÚJO, 2000, p. 47-51). Esses estereótipos, entre outros, são reflexos do racismo como era reproduzido em Hollywood e na televisão estadunidense. Contra esses e qualquer outra forma de estereótipo se erigiu o Manifesto Dogma Feijoada.

A atenção a uma representação humana e respeitosa do negro no cinema, diferente dos tipos apontados no parágrafo anterior, já permeava os anseios do ativismo negro brasileiro, pautando com frequência instâncias públicas e privadas no que tangia à presença de outros tipos étnicos componentes da diversidade étnico-racial brasileira na mídia (representatividade) e à

\footnotetext{
7 A Embrafilme, Empresa Brasileira de Filmes S.A., foi uma empresa estatal brasileira de economia mista, produtora e distribuidora de filmes cinematográficos. Foi criada em 12 de setembro de 1969 e vinculada ao então Ministério da Educação e Cultura como braço do Instituto Nacional do Cinema (INC). Enquanto existiu, sua função foi fomentar a produção e distribuição de filmes brasileiros. Foi extinta em 16 de março de 1990, sem a abertura de qualquer processo administrativo e/ou discussão pública que pudesse reorientar sua missão e a estratégia pelo Programa Nacional de Desestatização (PND) do governo de Fernando Collor de Mello.

${ }^{8}$ A Lei n. 8.313, de 23 de dezembro de 1991, tem como finalidade incentivar a produção de cultura em todo o país. Através dessa Lei, ficou instituído o Programa Nacional de Apoio à Cultura (PRONAC), cuja finalidade é captar e canalizar recursos para a cultura nacional em geral. É aplicada na forma de Mecenato e do Fundo Nacional de Cultura. O Mecenato é um de seus mecanismos de captação de recursos e consiste na concessão de renúncia fiscal às empresas que investem em cultura. A área de atuação da Lei Rouanet inclui artes cênicas, produção audiovisual, música, artes plásticas, patrimônio cultural, humanidades e edição de livros.

9 A Lei n. 8.685, de 20 de julho de 1993, é um mecanismo de apoio indireto a projetos audiovisuais. "Indireto" porque se dá através de incentivo fiscal. Ou seja, permite que contribuintes (pessoas físicas e jurídicas) tenham abatimento ou isenção de tributos, desde que direcionem recursos a projetos audiovisuais aprovados na Agência Nacional do Cinema (Ancine). A lei difere dos mecanismos de "fomento direto", nos quais a Ancine apoia projetos por meio de editais e seleções públicas. Seria válida até 2017, mas foi estendida até 2022.
} 
ressignificação da imagem do negro (representação), suscitando debates e formulando estratégias de ação (CARVALHO, DOMINGUES, 2018, p. 3).

Trazendo a discussão para nossos dias, o Festival de Cinema de Brasília, ocorrido em 2017, foi um marco ao deixar explícito que houve uma guinada na cognição social no que diz respeito às perspectivas / expectativas do cinema nacional diante de questões ignoradas e silenciadas anteriormente, como raça e racismo. O debate acerca do filme Vazante ${ }^{10}$, de Daniela Thomas, tensionou não somente a sub-representação do negro no cinema nacional, mas também a forma como negros e negras continuam sendo representados. Não obstante, toda a polêmica levantada a partir das críticas dirigidas ao filme Vazante revela uma tendência à perpetuidade de certas visões enraizadas e introjetadas no imaginário social e no inconsciente coletivo, quase que justificadas pelo "mito da democracia racial".

Outra tendência que demarca a ascensão do Cinema Negro é a profusão de festivais com a temática, destacando-se o Encontro de Cinema Negro Zórimo Bulbul: Brasil África e Caribe. Como já tratado por Borges e Oliveira $(2017,2018)$ e muitos outros autores, Zózimo Bulbul sempre merece uma menção honrosa, quando se fala de Cinema Negro no Brasil. Falemos sobre ele, ainda que de maneira breve.

Zózimo Bulbul lançou, em 1974, um curta-metragem que acabou por se tornar uma referência da produção cinematográfica negra do Brasil: Alma no Olho ${ }^{11}$. O filme tem como proposta contar, durante 11 minutos, a história de povos negros sequestrados de seus países do continente africano para serem escravizados e terem sua humanidade cassada nas Américas e na Europa. É importante registrar que Alma no Olho não faz uso da palavra e que os idiomas utilizados são ritmos africanos e da diáspora africana, a música de John Coltrane e o corpo de Zózimo: linguagens universais, facilmente compreendidas por quem assiste ao filme. Esta obra acabou por se tornar referência para quem, desde então, produz Cinema Negro no Brasil e é muito significativo o número de jovens negros e negras que citam Zózimo Bulbul e Alma no Olho como inspirações para a sua produção fílmica.

Considerado pela crítica como uma obra-prima, premiado na VI Jornada Brasileira de Curta-Metragem (Salvador/BA, 1977), Prêmio EMBRAFILME - Troféu Humberto Mauro, Alma no Olho faz uma reflexão sobre a identidade negra no Brasil, através de linguagem corporal, focalizando a origem africana, a colonização europeia e a libertação pela identidade cultural. A importância e simbologia do curta-metragem de 11 minutos de Bulbul vai muito além das questões técnicas e estéticas, mas é um marco do cinema no Brasil e está totalmente enquadrado naquilo que posteriormente foi definido como Cinema Negro.

Após Alma no Olho, Zózimo produziu vários filmes e foi bastante premiado com eles: dirigiu e atuou nos curta-metragens Aniceto do Império em Dia de Alforria (1981) e Pequena África (2002); também dos média-metragens Samba no Trem (2000/2001), República de Tiradentes (2004/2005), Zona Carioca do Porto (2006), Referencias (2006) e Renascimento Africano (2010); e do longa-metragem Abolição" (1988). Por esses filmes, Zózimo recebeu mais de 15 prêmios. Além disso, Bulbul atuou em mais de 30 filmes.

Por ter sido um homem que buscava realizar seus sonhos, desde a década de 1980 investiu na criação de um espaço de referência da cultura afro-brasileira. Aos 70 anos de idade, em 2007, Zózimo criou o Centro Afrocarioca de Cinema, no bairro da Lapa, Rio de Janeiro, e, em conjunto,

10 Data de lançamento 9 de novembro de 2017. Duração: 1h40min. Direção: Daniela Thomas. Roteiro: Daniela Thomas, Beto Amaral. Gêneros Drama, Histórico. Nacionalidade Brasil. Produtora: Cisma Produções, Dezenove Som e Imagens, de Sara Silveira, e Ukbar Filmes. Coprodução: Globo Filmes. Distribuidor brasileiro (Lançamento): Europa Filmes. Classificação: 14 anos.

${ }^{11}$ Alma no Olho (Brasil, 1973). Gênero: Experimental. Direção, Montagem e Produção: Zózimo Bulbul; Imagem: José Ventura; Elenco: Zózimo Bulbul; Duração: 12 min . Local de produção: Rio de Janeiro / Cor: P\&B; Prêmio: Melhor Filme na Jornada Internacional de Cinema da Bahia, em 1977. 
criou também o Encontro de Cinema Negro. Os Encontros, que acontecem anualmente desde essa data, têm colaborado para a ascensão da luta antirracista no cinema, e, hoje, se constituem como a maior mostra regular de Cinema Negro em toda a América Latina. Além disso, o Centro Afrocarioca de Cinema constituiu-se em um espaço de formação educacional, um lugar que colabora para a reflexão e prática de uma pedagogia antirracista. Trataremos disso, um pouco mais detidamente, na seção seguinte.

\section{A ESCOLA E A LUTA ANTIRRACISTA: O CENTRO AFROCARIOCA DE CINEMA COMO UM ESPAÇO PRIVILEGIADO DE FORMAÇÃO}

Como é de amplo conhecimento, a Lei n. 10.639/2003 (BRASIL, 2003), que alterou a Lei de Diretrizes e Bases da Educação Nacional, tornou obrigatório o ensino sobre História e Cultura Afro-Brasileira e Africana. Como já apontado em um número significativo de artigos, pesquisas, teses de doutorado e dissertações de mestrado, essa Lei nos orienta à compreensão de que as pessoas negras sequestradas para o Brasil e seus/suas descendentes não foram meros colaboradores na construção desse país, de sua cultura e de suas riquezas, mas, embora apagados / invisibilizados historicamente, foram protagonistas de todos os fatos que constituem o Brasil, inclusive e, talvez, principalmente, do processo de abolição formal do trabalho escravo. A Lei n. 10.639/2003 e suas Diretrizes Curriculares (BRASIL, 2004) propõem uma mudança de postura que caminha na contramão da cultura / formação eurocêntrica à qual a grande maioria de nós obteve por intermédio dos currículos oficiais a que fomos submetidos.

Essa mudança de postura gerou impactos bastante positivos na construção identitária de cidadãos e cidadãs brasileiros(as), ao propor a ruptura da história brasileira, contada exclusivamente pelo viés do colonizador europeu branco, e por incorporar, também, de forma legítima e autêntica, a produção e os saberes de pessoas negras e indígenas.

Não é aceitável que, em um país cuja população se autodeclare majoritariamente negra, o corpo e a pele dessas pessoas não estejam representados na mídia cinematográfica produzida aqui. A cinematografia excessivamente branca do Brasil (CANDIDO et al., 2014) revela e cultiva uma grave patologia que traz consequências desastrosas para todos/as, pois consumir uma produção midiática impregnada de preconceitos e estereótipos racistas afeta a estrutura psíquica não só dos discriminados, mas de todos os que fazem parte dessa sociedade (MUNANGA, 2005, p. 12).

O traço pedagógico da diversidade é algo complexo, pois exige o reconhecimento da diferença e, ao mesmo tempo, o estabelecimento de padrões de respeito, de ética e a garantia dos direitos sociais. Refletir pedagogicamente sobre a diversidade cultural significa reconhecer as diferenças, respeitá-las, aceitá-las e colocá-las na pauta das nossas reivindicações, no cerne do processo educativo. O reconhecimento das diferenças não é algo fácil, nos leva a passar em revista as nossas ações, opções políticas e individuais e os nossos valores, rompendo com os preconceitos, superando as velhas opiniões formadas sem reflexão (GOMES, 1999).

Vale ressaltar, todavia, que apenas a lei não basta para promover, de fato, uma mudança curricular em nossas escolas, na formação e na prática dos profissionais da educação. Os obstáculos na abordagem de temáticas referentes às relações étnico-raciais e ao racismo ainda são desafios a serem vencidos de forma plena pela escola:

A escola pode ser considerada, então, como um dos espaços que interferem na construção da identidade negra. O olhar lançado sobre o negro e sua cultura, na escola, tanto pode valorizar identidades e diferenças quanto pode estigmatizá-las, discriminá-las, segregá-las e até mesmo negá-las. (GOMES, 2003, p. 176). 
Considerável número de profissionais de educação diz não perceber os conflitos e as discriminações raciais (MEC/SECAD, 2005, p. 12; SOUSA, LIMA, 2013, p. 25-190). Nas palavras de Kabengele Munanga:

Alguns professores, por falta de preparo ou por preconceitos neles introjetados, não sabem lançar mão das situações flagrantes de discriminação no espaço escolar e na sala como momento pedagógico privilegiado para discutir a diversidade e conscientizar seus alunos sobre a importância e a riqueza que ela traz à nossa cultura e à nossa identidade nacional. (MUNANGA, 2005, p. 15).

Munanga assinala o despreparo ainda existente entre profissionais de educação para lidar com situações conflituosas no cotidiano escolar que envolvam a discriminação étnico-racial, bem como para fazer da sala de aula um espaço de reflexão sobre a diversidade cultural brasileira. Como trabalhar tais temas de forma que despertem o interesse e, mais que isso, a sensibilidade de jovens que interiorizaram e naturalizaram as práticas discriminatórias desde a infância, presentes nos discursos testemunhados nos espaços de convivência social e reforçadas pelos meios de comunicação de massa?! Os espaços de formação diferentes dos da "escola formal" ou "escola oficial", como ONGs, Pontos de Cultura e similares, oferecem alternativas para a inflexão desejada na escola, colaborando para a formação de uma educação antirracista. Com o objetivo de corroborar nossos argumentos, apresentaremos a seguir alguns dos objetivos do Centro Afrocarioca de Cinema.

De acordo com os projetos de Zózimo Bulbul (BULBUL, 2012), o Centro Afrocarioca de Cinema tem como objetivo constituir um espaço onde pessoas negras possam exibir seus filmes e possam ver a produção cinematográfica da diáspora negra de todo o mundo. Para além disso, o Centro Afrocarioca tem-se constituído também como um espaço de formação não somente de cineastas, roteiristas e produtores de audiovisual negro, mas ainda como um importante locus de formação de público, de uma plateia sintonizada com a crítica antirracista no audiovisual.

Os projetos formativos do Centro Afrocarioca têm como objetivos: 1) o questionamento da realidade através do cinema, formulando problemas e buscando resolvê-los; 2) a construção de parcerias internacionais entre cineastas brasileiros e do exterior, como também entre professores e pesquisadores, visando aprimorar a produção do conhecimento sobre cinematografia; 3) propiciar aumento de visibilidade e de formação a jovens cineastas, através de núcleos criativos de roteiro em cursos de extensão; 4) atrair discentes dos mais diferentes níveis (ensino fundamental, médio, graduação e pós-graduação) e o público em geral, promovendo ações culturais que afirmem o olhar afro-brasileiro, para que as novas gerações alcancem uma verdadeira inclusão social através de novos olhares, novas estéticas, novos saberes, que espelhem as diferentes identidades na nossa formação como povo brasileiro; 5) desenvolver a capacidade de utilizar diferentes fontes de informação e recursos tecnológicos para adquirir e construir conhecimentos no campo do cinema; 6) compartilhar conhecimentos com o público em geral a respeito das produções cinematográficas afro-brasileiras, africanas e caribenhas, de sua diversidade e a respeito da variedade de linguagens utilizadas pelo cinema; 7) propiciar espaços de diálogo e reflexão tendo por base a postura crítica, responsável e construtiva diante da realidade representada e/ou construída pelo cinema, entre outros.

As artes têm reconhecido a centralidade das tensas relações étnico-raciais que acompanham a nossa formação social e cultural (GOMES, 2012, p. 100). Gomes (2012, p. 103) relata um caso de uma professora que admitiu que a Lei n. 10.639/2003 a levou a assistir a uma peça teatral sobre o capoeirista Besouro e, a partir disso, fala-nos sobre como a composição tripartite entre legislação / educação / arte pode render resultados produtivos, sendo a educação o pilar de sustentação do desenvolvimento cognitivo e intelectual; a arte a união entre o cultural e o lúdico e proporcionando 
leveza à aquisição de conhecimento; e a legislação o aporte jurídico e legal para que se atinjam resultados que favoreçam toda a sociedade.

Entendemos, assim como Gomes (2012), a importância e os significativos avanços advindos da atual legislação, bem como sua potencialidade de oportunizar desdobramentos e impactos na educação formal e nas relações sociais, que podem ser didaticamente transmitidos através de recursos artísticos e culturais, como o Cinema Negro e o espaço formativo do Centro Afrocarioca de Cinema Zózimo Bulbul.

\section{CONSIDERAÇÕES FINAIS}

As lutas do antirracismo são travadas nas dinâmicas políticas dos movimentos sociais e na cultura visual. Segundo bell hooks (2019, p. 37), "[...] abrir espaço para imagens transgressoras, para a visão rebelde fora da lei, é essencial em qualquer esforço para criar um contexto de transformação". Romper com os paradigmas do colonialismo e racismo na representação da experiência negra e da negritude constitui uma luta travada na arte, na educação e em políticas de imagens.

O Cinema Negro é, então, um dos vetores de imagens transgressoras na contemporaneidade. Quando diretores negros com vínculos com o Cinema Novo elaboraram críticas ao racismo no cinema e audiovisual brasileiro, eles fomentaram estéticas distintas, produzindo visualidades que transgrediam os regimes dominantes de representação da experiência negra. Ao defenderem a representatividade dos negros no campo do cinema e audiovisual e ao criticarem a estereotipia dos afro-brasileiros na cultura visual, as várias gerações comprometidas com o Cinema Negro estabeleceram saberes e pedagogias emergentes comprometidas com o antirracismo (GOMES, 2017).

Um dos marcos do Cinema Negro foi a produção cinematográfica do ator e diretor Zózimo Bulbul. Além de curtas, médias e longa metragens identificadas com a negritude, Zózimo construiu o Centro Afrocarioca de Cinema e o Encontro de Cinema Negro em 2007. Nesse centro de cultura, bem como nos festivais que promoveu, os(as) diretores(as), as produtoras e os coletivos de negros(as) estabeleceram saberes comprometidos com o autoamor à negritude e com a decolonização da forma de olhar e representar o Brasil. As imagens transgressoras do Cinema Negro são plurais em suas trajetórias e formas de expressão, mas têm encontrado em Zózimo Bulbul uma das referências mais importantes para a construção de suas lutas estéticas e políticas.

\section{REFERÊNCIAS}

ARAÚJO, Joel Zito. A negação do Brasil. O negro na telenovela brasileira. São Paulo: SENAC, 2000. BORGES, Roberto; OLIVEIRA, Samuel Silva Rodrigues de. Encontros de cinema negro: práticas culturais e estética afrodiaspórica de Zózimo Bulbul. In: LOANGO, Anny Ocoró; CORDEIRO, Maria José de Jesus Alves (org.). Negritudes e africanidades na América Latina e no Caribe. 1. ed. Franca: Ribeirão Gráfica Editora, 2018, v. 2, p. 100-109.

BORGES, Roberto; OLIVEIRA, Samuel Silva Rodrigues de. Família e comensalidade em filhas do vento: luta antirracista na teledramaturgia brasileira. In: VARGAS, Eliane Portes et al. (org.). Cinema e comensalidade 2. 1. ed. Curitiba: CRV, 2017, v. 2, p. 109-126.

BRASIL Lei n. 10.639, de 9 de janeiro de 2003. Brasília, DF, 2003. Disponível em http://www.planalto.gov.br/ccivil_03/leis/2003/L10.639.htm. Acesso em 17 ago. 2017.

BRASIL. Resolução n. 1, de 17 de junbo de 2004. Brasília, DF, 2004. Disponível em http://portal.mec.gov.br/cne/arquivos/pdf/res012004.pdf. Acesso em 2 abr. 2020. 
BULBUL, Zózimo et al (org.). Zózimo Bulbul - uma alma carioca. Rio de Janeiro: Centro Afro Carioca de Cinema, 2012.

CANDIDO, Marcia Rangel et al. A cara do cinema nacional: gênero e cor dos atores, diretores e roteiristas dos filmes brasileiros (2002-2012). (Textos para discussão). Rio de Janeiro: GEMAA / IESP, 2014.

CARVALHO, Noel dos Santos. Cinema e representação racial: o cinema negro de Zózimo Bulbul. Tese (Doutorado em Sociologia). Universidade de São Paulo, São Paulo, São Paulo, 2005.

CARVALHO, Noel. Cinema em negro e branco. In: PENHA DE SOUZA, Edileuza. Negritude, cinema e educação: caminhos para a implementação da Lei 10.639/03. Belo Horizonte: Mazza, 2006. p. 17-30.

CARVAlHO, Noel dos Santos; DOMINGUES, Petrônio. Dogma Feijoada: A invenção do Cinema Negro brasileiro. Revista Brasileira de Ciências Sociais, dez. 2018, v. 33, n. 96, p. 1-18.

GOMES, Nilma Lino. Educação, identidade negra e formação de professores/as: um olhar sobre o corpo negro e o cabelo crespo. Educação e Pesquisa, São Paulo, v. 829, n. 1, p. 167-182, jan./jun. 2003.

GOMES, Nilma Lino. Educação e Diversidade Cultural: refletindo sobre as diferentes presenças na escola. 1999. Disponível em http://www.mulheresnegras.org/nilma.html. Acesso em 22 maio 2020.

GOMES, Nilma Lino. Relações raciais e descolonização dos currículos. Currículo sem Fronteiras, v. 12, n. 1, p. 98-109, jan./abr. 2012.

GOMES, Nilma Lino. O movimento negro educador - saberes construídos nas lutas por emancipação. Petropólis, Rio de Janeiro: Vozes, 2017.

HALL, Stuart. Cultura e representação. Rio de Janeiro: Puc-Rio: Appicuri, 2016.

HOOKS, bell. Olhares negros: raça e representação. São Paulo: Ed. Elefante, 2019.

LOBO, Mory Marcia de Oliveira. O cinema negro como arte de afirmação frente a um possível mal-estar na educação contemporânea. In: EDUCERE. Anais do XII Congresso Nacional de Educação. Curitiba: EDUCERE, 2015. p. 1621-1634.

MUNANGA, Kabengele (org.). Superando o racismo na escola. 2. ed. Brasília: Ministério da Educação, Secretaria de Educação Continuada, Alfabetização e Diversidade, 2005.

NEVES, David. O cinema de assunto e autor negros no Brasil. In: AUGUSTO, Heitor (org.). Catálogo do $20^{\circ}$ Festival Internacional de Curtas de Belo Horizonte. Belo Horizonte: Fundação Clóvis Salgado, 2018. p. 183-186.

OSORIO, Rafael Guerreiro. A desigualdade racial da pobreza no Brasil. (Texto para Discussão / Instituto de Pesquisa Econômica Aplicada). Brasília: Rio de Janeiro: Ipea, 2019.

PRUDENTE, Celso. Cinema negro: pontos reflexivos para a compreensão da importância da II Conferência de Intelectuais da África e da Diáspora. Revista Palmares. Cultura Afro-brasileira, Brasília, n. 3, p. 48-50, 2006. Disponível em http://www.palmares.gov.br/?page id=6320\#footer. Acesso em 22 maio 2020.

STAM, Robert. Multiculturalismo tropical - uma história comparativa da raça na cultura e no cinema brasileiro. São Paulo: Edusp, 2008.

SANTOS, Júlio César dos. A quem interessa um "Cinema Negro"? Revista da ABPN, v. 5, n. 9, nov.-fev. 2013, p. 98-106. 


\section{Informações dos autores}

Hélio Lucio dos Reis Ventura

Mestrando do Programa de Pós-graduação em Relações Étnico-raciais do Cefet-RJ e professor do PVNC e da SEEDUC-RJ

E-mail: prof.helioventura@gmail.com

ORCID: https://orcid.org/0000-0002-0269-0346

Link Lattes: http://lattes.cnpq.br/5330199552794987

Samuel Silva Rodrigues de Oliveira

Professor do Programa de Pós-graduação em Relações Étnico-raciais do Cefet-RJ

E-mail:samu_oliveira@yahoo.com.br

ORCID: https://orcid.org/0000-0002-3771-9057

Link Lattes: http://lattes.cnpq/1492578610570434

Roberto Borges

Professor do Programa de Pós-graduação em Relações Étnico-raciais do Cefet-RJ

E-mail: borgesrcs@gmail.com

ORCID: https://orcid.org/0000-0001-9373-748X

Link Lattes: http//lattes.cnpq.br/0638289717015836 